\title{
Effect of nano-hydroxyapatite on protein adsorption and cell adhesion of poly(lactic acid)/nano-hydroxyapatite composite microspheres
}

\author{
H. M. C. Suboda Wijerathne ${ }^{1,2} \cdot$ Dong Yan ${ }^{1} \cdot$ Bin Zeng $^{1} \cdot$ Yanping Xie ${ }^{1} \cdot$ Hongchao Hu$^{1} \cdot$ M. Nirmali Wickramaratne ${ }^{2}$. \\ Yingchao $\operatorname{Han}^{1}$ (1)
}

Received: 18 January 2020 / Accepted: 14 March 2020 / Published online: 20 March 2020

(c) Springer Nature Switzerland AG 2020

\begin{abstract}
Surface properties of biomaterials are significant as they are intended to interact with biological system interfaces. This study was aimed to reveal the effect of nano-hydroxyapatite (Nano-HAP) on the properties of poly(lactic acid) (PLA) microspheres. Nano-HAP particles of 10-30\% content were successfully embedded in PLA microspheres by emulsion solvent evaporation method. The incorporation of Nano-HAP particles resulted in the increases of surface hydrophilicity and surface rough of microspheres that depended on the content of Nano-HAP. With the increase of Nano-HAP content, the adsorption capacity for protein of PLA/Nano-HAP composite microspheres was increased significantly. Moreover, the incorporation of Nano-HAP could promote the adhesion and proliferation of rat Mesenchymal Stem cells (rMSCs) on microspheres, which could be attributed to the component of Nano-HAP as well as the increases of surface hydrophilicity and rough. In addition, PLA/Nano-HAP composite microspheres showed significant promotion on osteogenic differentiation of rMSCs due to the facilitation of Nano-HAP. Accordingly, the incorporation of Nano-HAP could improve the physicochemical and biological properties of PLA microspheres, and the resulting PLA/Nano-HAP composite microspheres could be expected to achieve good application in tissue repair.
\end{abstract}

Keywords Poly(lactic acid) $\cdot$ Nano hydroxyapatite $\cdot$ Protein adsorption $\cdot$ Cell proliferation

\section{Introduction}

Surgical involvements are required for severe bone defects associated with trauma, tumor and other infections. Tissue engineering is a promising strategy for bone regeneration in repairing massive bone defects [1, 2]. There into, the biomaterials with higher potential of bone regeneration are crucial for repairing bone defects. Moreover, protein adsorption onto biomaterials is very important as it is the basic step of changing surface properties to biological properties. The composition and conformation of the adsorbed protein layer is considered to be one of the major factors in determining the nature of cell interaction with the materials. The enhancement of cell adhesion and proliferation on the bone scaffolds is usually responsible for eventual tissue integration and the amount of new bone formation [3-5].

H. M. C. Suboda Wijerathne and Dong Yan: Co-first authors.

Electronic supplementary material The online version of this article (https://doi.org/10.1007/s42452-020-2531-8) contains supplementary material, which is available to authorized users.

$\triangle$ Yingchao Han, hanyingchao@whut.edu.cn | ${ }^{1}$ State Key Laboratory of Advanced Technology for Materials Synthesis and Processing, Biomedical Materials and Engineering Research Center of Hubei, Wuhan University of Technology, Wuhan 430070, Hubei,

People's Republic of China. ${ }^{2}$ Department of Physical Sciences and Technology, Faculty of Applied Sciences, Sabaragamuwa University of Sri Lanka, Belihuloya 70140, Sri Lanka. 
Poly(lactic acid) (PLA) is a promising candidate as tissue engineering scaffold due to its good biocompatibility and biodegradability. However, pure PLA shows a hydrophobic surface and the acidic degradation product easily causes aseptic inflammation, which are not conducive to the adhesion and proliferation of cells. Hydroxyapatite (HAP) is the major inorganic component of human bones, and has good biocompatibility, bioactivity and osteogenic activity. It exists as Nano crystals in the organic/inorganic composite structure of human bones. The incorporation of HAP can endow the bioactivity and osteogenic activity, and improve cell affinity [6-8]. Therefore, the organic/inorganic composites by mimicking natural bone attract attentions, aiming to improve the natural process of bone regeneration.

Microspheres as injectable scaffolds are among highly effective candidates for the application of bone defect repair [9-13]. In this study, PLA/Nano-HAP composite microspheres were prepared, and the effect of NanoHAP on the surface property of microspheres including hydrophilicity, protein adsorption and cell adhesion was investigated. This study is strictly aimed to the improvement of protein adsorption, cell adhesion and proliferation of PLA microspheres, which is significant and highly demanded for applications of PLA in bone tissue engineering.

\section{Experimental procedure}

\subsection{Materials}

Analytical pure $\mathrm{CaCl}_{2} \cdot 2 \mathrm{H}_{2} \mathrm{O},\left(\mathrm{NH}_{4}\right)_{2} \mathrm{HPO}_{4}, \mathrm{NH}_{4} \mathrm{OH}$ and dichloromethane (DCM) were perchased from Sinopharm Chemical Reagent Co., Ltd. Analytical pure polyvinyl alcohol (PVA) was purchased from Aladdin. Biomedical grade PLA with a molecular weight of 100,000 was purchased from JINAN Daigang BIO Engineer Limited Co.

\subsection{Preparation of Nano-HAP}

$0.0334 \mathrm{~mol} / \mathrm{L} \mathrm{CaCl} \cdot 2 \mathrm{H}_{2} \mathrm{O}$ aqueous solution and $0.02 \mathrm{~mol} / \mathrm{L}$ $\left(\mathrm{NH}_{4}\right)_{2} \mathrm{HPO}_{4}$ was prepared by ultrapure (UP) water. Then $\left(\mathrm{NH}_{4}\right)_{2} \mathrm{HPO}_{4}$ aqueous solution was introduced to $\mathrm{CaCl}_{2} \cdot 2 \mathrm{H}_{2} \mathrm{O}$ solution with $1: 1$ of volume to volume ratio and the mixture was stirred with magnetic stirrer. Concentrated $\mathrm{NH}_{4} \mathrm{OH}$ was added to the mixture with 3:200 of volume to volume ratio $\left(\mathrm{NH}_{4} \mathrm{OH}\right.$ : solution) in order to maintain the $\mathrm{pH}$ of the solution between 9 and 10. This mixture was maintained at $37^{\circ} \mathrm{C}$ for three hours to prepare Nano-HAP.

SN Applied Sciences

\subsection{Preparation of PLA/Nano-HAP composite microspheres}

PLA/Nano-HAP composite microspheres were prepared by emulsion solvent evaporation method. $5 \mathrm{mg} / \mathrm{mL}$ PVA aqueous solution (water phase) was prepared by dissolving PVA in UP water and $50 \mathrm{mg} / \mathrm{mL}$ PLA solution (oil phase) was prepared by dissolving PLA in DCM. $0.25 \mathrm{~g}$, $0.5 \mathrm{~g}$ and $0.75 \mathrm{~g}$ of Nano-HAP was introduced to PLA solution and ultrasonically dispersed for one minute in order to prepare $10 \%, 20 \%$ and $30 \%$ Nano-HAP contained composite microspheres, respectively. Then PLA/ Nano-HAP mixture was introduced to PVA solution with 1:10 of oil to water ratio and the mixture was mechanically agitated for $240 \mathrm{~min}$. Then the obtained microspheres were washed three times with UP water and separated by centrifugation. Finally the samples were freeze dried and used for further analysis.

\subsection{Characterization of samples}

X-ray diffraction (XRD, D/Max-IIIA, Rigaku Co., Tokyo, Japan) and fourier transform infrared spectroscopy (FTIR, Thermo Nicolet 6700, USA) were used to identified Nano-HAP. Microstructure of sample was characterized by field emission scanning electron microscope (FESEM, Zeiss Ultra Plus) and transmission electron microscope (TEM, JEM-1400Plus). The wetting property of sample was measured using contact angle meter (JC2000C, POWEREACH).

\subsection{Analysis of protein adsorption of samples}

BSA standard solution series $(0.2-5.0 \mathrm{mg} / \mathrm{mL})$ were prepared by serial dilution of $5.0 \mathrm{mg} / \mathrm{mL}$ BSA stock solution with PBS. BCA A and BCA $B$ from the protein assay kit (Beyotime, China) was mixed with 1:50 ratio to obtain the protein assay mixture. $20 \mu \mathrm{L}$ BSA standard solution series were added in 96-wells plate and $200 \mu \mathrm{L} B C A$ solution was added subsequently. After incubation of $30 \mathrm{~min}$ at $37^{\circ} \mathrm{C}$, the absorbance was measured at $562 \mathrm{~nm}$ using microplate reader (Multiskan Go, Thermo Scientific). The standard curve was obtained while BSA concentration was from $0.2 \mathrm{mg} / \mathrm{mL}$ to $1.8 \mathrm{mg} / \mathrm{mL}$ $\left(\mathrm{Y}=0.02649+0.45892 \mathrm{X}, \mathrm{R}^{2}=0.9996\right)$.

The adsorption of BSA on microspheres vs time was carried out. $40 \mathrm{mg}$ of microsphere was put into $10 \mathrm{~mL}$ Eppendorf tube. Then, $10 \mathrm{~mL} 37^{\circ} \mathrm{C}$-incubated BSA solution $(1.0 \mathrm{mg} / \mathrm{mL})$ was added and Eppendorf tube was incubated at $37^{\circ} \mathrm{C}$. At setting incubation times of 0.5 , 
1.0, 1.5, 2.0, 3.0, 5.0 and $7.0 \mathrm{~h}, 20 \mu \mathrm{L}$ aliquots were collected for BCA assay, respectively. $P$ values were calculated from SPSS statistical software.

Similarily, the adsorption of BSA on microspheres vs BSA concentration was also carried out. All samples were incubated at $37^{\circ} \mathrm{C}$ for $4 \mathrm{~h}$.

\subsection{In vitro cellular evaluation}

Rat mesenchymal stem cells (rMSCs) were seeded and cultured on microspheres to assess the biological properties of microspheres. In cell adhesion test, after 7 and 14 days of cell culture, anti-osteopontin (OPN) antibody was added to recognize OPN. Then FITC-conjugated secondary antibody was used to complete the immunostaining. Cell nuclei were stained with DAPI. After immunostaining, cells were observed by fluorescence microscope (Nikon Eclipse Cl, Japan). To further observe the morphology of cells on microspheres, cells were fixed and then examined by SEM (TESCAN, VEGA3LMU) on day 14. ALP assay was performed by the modified Gomori's calcium-cobalt method and examined with biological microscope (Nikon Eclipse $\mathrm{Cl}$ ) on day 7 and 14. Mineralized nodules stained with alizarin red were observed by biological microscope (Nikon Eclipse $\mathrm{Cl}$ ) on day 21.

\section{Results and discussion}

\subsection{Characterization of Nano-HAP and microspheres}

The Nano-HAP was first synthesized for the preparation of PLA/Nano-HAP composite microspheres. The XRD pattern (Fig. S1 (a)) showed the broadened diffraction peaks assigned to HAP (JCPDS 84-1998), indicating a low crystallinity of resulting sample. The FTIR spectrum (Fig. S1 (b)) further displayed the characteristic vibrations assigned to $\operatorname{HAP}\left(3563 \mathrm{~cm}^{-1}: \mathrm{OH}\right.$ - group in HAP; $1104 \mathrm{~cm}^{-1}, 1035 \mathrm{~cm}^{-1}$, $963 \mathrm{~cm}^{-1}, 603 \mathrm{~cm}^{-1}, 565 \mathrm{~cm}^{-1}$ and $472 \mathrm{~cm}^{-1}: \mathrm{PO}_{4}{ }^{3-}$ group in HAP) $[14,15]$. TEM observation (Fig. S2) revealed that sample consisted of short rod-like Nanoparticles with size of about $35.78 \mathrm{~nm} \times 8.06 \mathrm{~nm}$.

Figure S3 illustrates the SEM images of pure PLA microspheres and PLA/Nano-HAP composite microspheres, respectively. Results showed that the regular microspheres of PLA and PLA/Nano-HAP composite were obtained. The mean diameter of pure PLA microspheres was $16.55 \pm 9.47 \mu \mathrm{m}$. With the incorporation of Nano-HAP, the mean diameter of PLA/Nano-HAP composite microspheres was increased to about $30 \mu \mathrm{m}$; however, the composite microspheres with $10 \%, 20 \%$ and $30 \%$ NanoHAP showed no significant difference in mean diameters $(29.86 \pm 6.47 \mu \mathrm{m}, 28.12 \pm 5.48 \mu \mathrm{m}$ and $29.81 \pm 5.33 \mu \mathrm{m})$.
Fig. 1 Surface morphology of microspheres. a Pure PLA; b PLA/10\% Nano-HAP; c PLA $/ 20 \%$ Nano-HAP; d PLA/30\% Nano-HAP
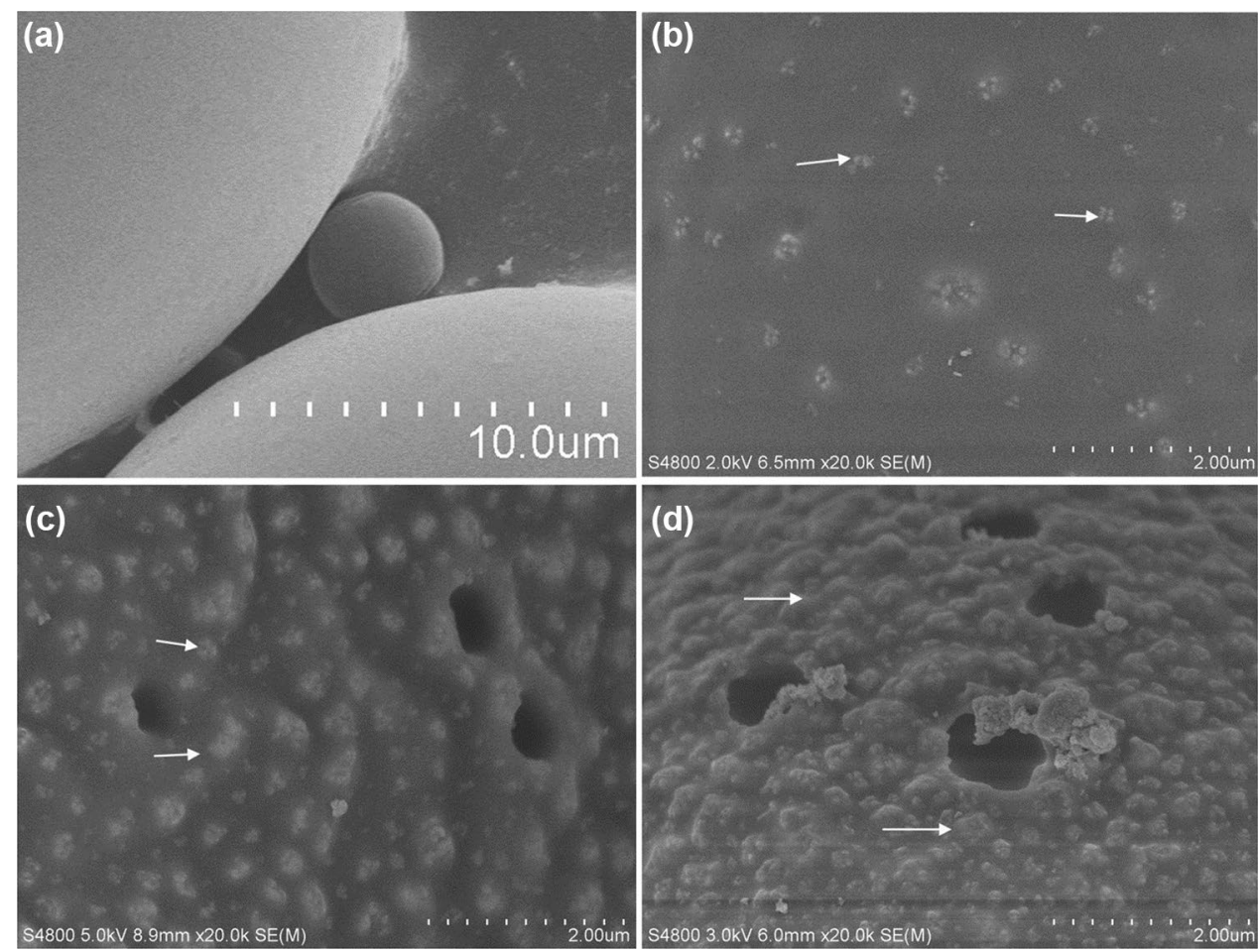
The surface morphology of microspheres was changed due to the incorporation of Nano-HAP (Fig. 1). The pure PLA microspheres had very smooth surface. However, the composite microspheres showed rough surface due to the incorporation of Nano-HAP. Moreover, the surface became much rougher with the increase of Nano-HAP content from 10 to $30 \%$. The Nano-HAP particles were embedded in PLA matrix. While the content of Nano-HAP was $10 \%$, Nano-HAP particles exhibited almost single-particle dispersion in PLA. At higher Nano-HAP content, NanoHAP particles were embedded in aggregations of about 200-400 nm; however, the distribution of Nano-HAP particles was almost uniform on micrometer scale. In addition, the elemental mapping test was used to reveal the distribution of Nano-HAP in composite microspheres (Fig. 2). The observed signals of Ca demonstrated that Nano-HAP particles were distributed uniformly in the surface layer of composite microspheres.

The surface hydrophilicity of microspheres was also varied with the incorporation of Nano-HAP as shown in Fig. 3. PLA microspheres, a hydrophobic polymer material, showed a contact angle of about $114^{\circ}$ to water. However, Nano-HAP, a hydrophilic inorganic material, displayed a contact angle of about $44^{\circ}$ to water. The contact angles of

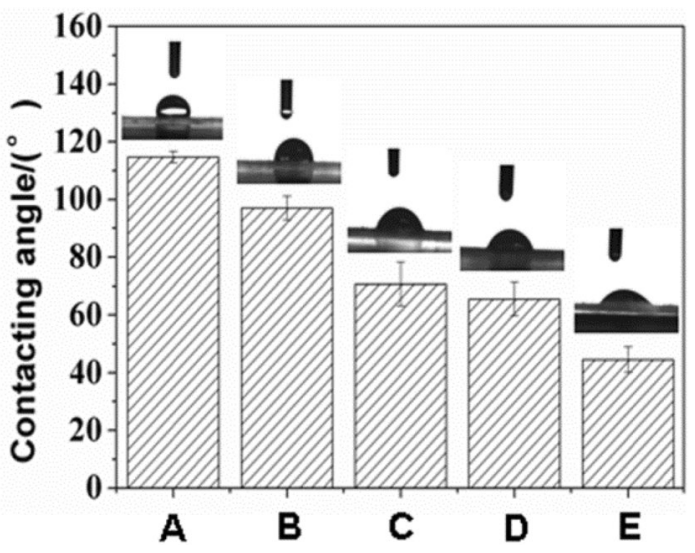

Fig. 3 Contact angle of microspheres and nHAP. A: pure PLA; B: PLA/10\% Nano-HAP; C: PLA/20\% Nano-HAP; D: PLA/30\% NanoHAP; E: $37^{\circ} \mathrm{C}$-synthesized Nano-HAP

composite microspheres with $10 \%, 20 \%$ and $30 \%$ NanoHAP were $97^{\circ}, 71^{\circ}$ and $66^{\circ}$, respectively. Compared to PLA microspheres, PLA/Nano-HAP composite microspheres showed an improvement of hydrophilicity due to the embedding of Nano-HAP, depending on the content of Nano-HAP.
Fig. 2 Elemental mapping (C, $\mathrm{O}, \mathrm{Ca}$ ) of PLA/10\% Nano-HAP composite microspheres
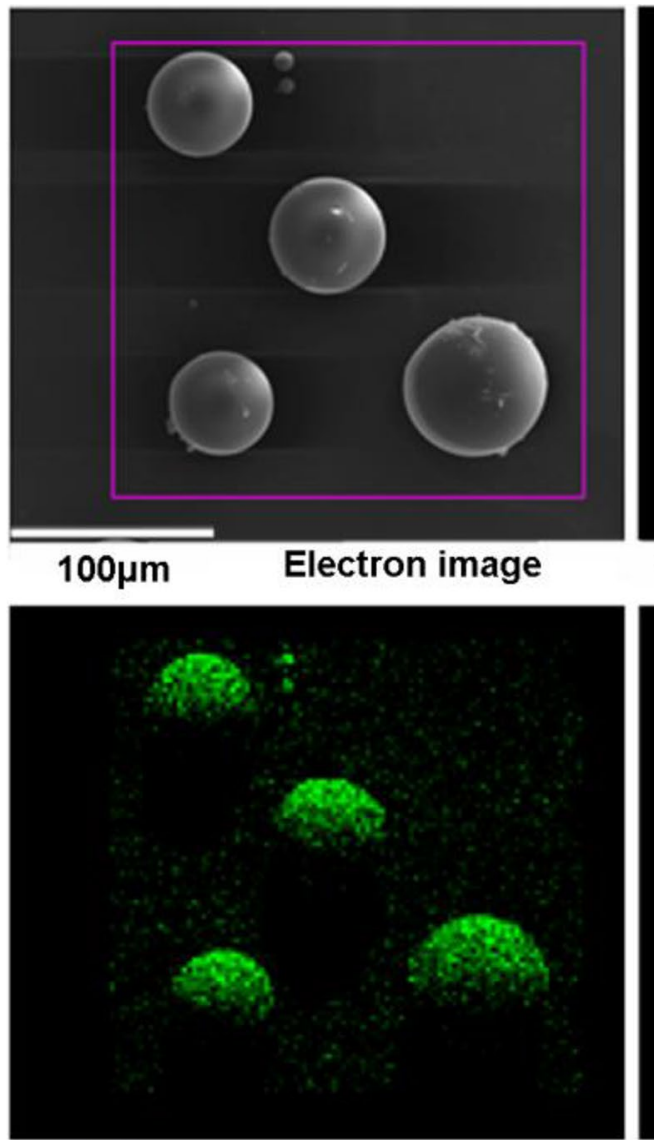

O Ka1

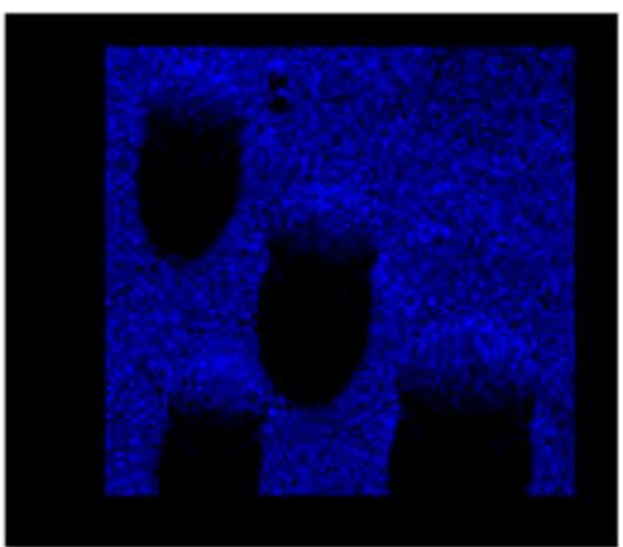

C Ka1

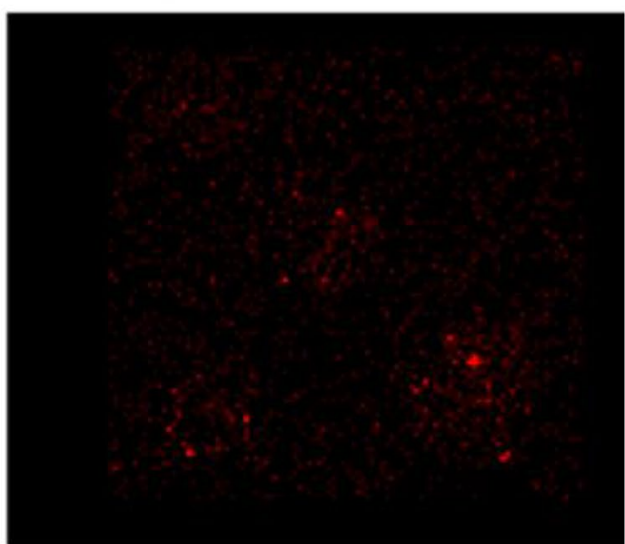

$\mathrm{Ca} \mathrm{Ka1}$ 


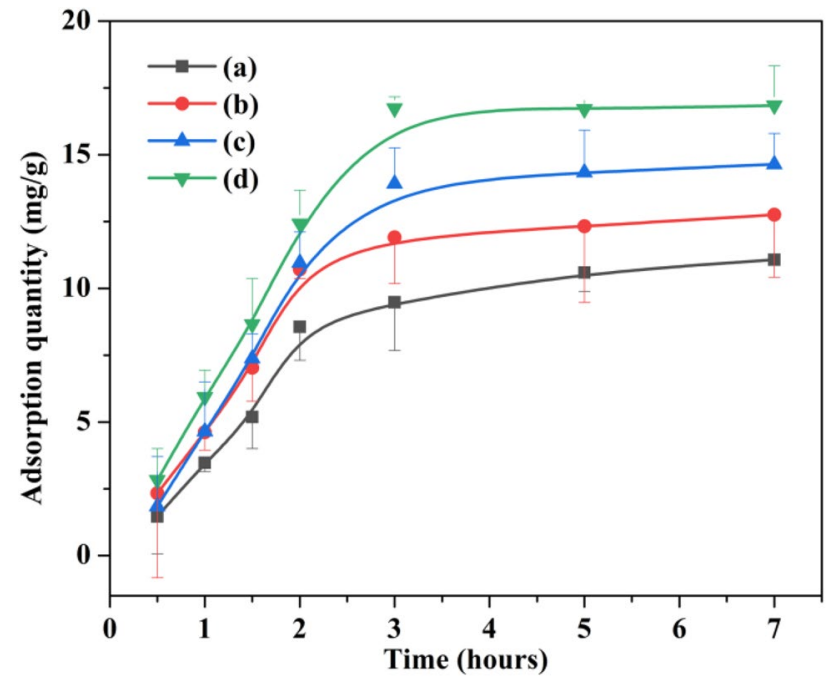

Fig. 4 The variation of BSA adsorption on microspheres with time. (a): pure PLA; (b): PLA/10\% Nano-HAP; (c): PLA/20\% Nano-HAP; (d): PLA/30\% Nano-HAP

\subsection{Analysis of protein adsorption of microspheres}

As shown in Fig. 4, PLA and PLA/Nano-HAP microspheres showed similar adsorption profiles for BSA with the increase of adsorption time. The BSA adsorption quickly increased in the first $3 \mathrm{~h}$ and then reached to an equilibrium. However, there were some differences between PLA microsphere and PLA/Nano-HAP microspheres. HAP has good adsorption property for protein and can be used as protein delivery system [16-18]. The incorporation of Nano-HAP resulted in a little increase of adsorption rate for BSA. In addition, at same time point, the adsorption quantity was significantly enhanced with the increase of NanoHAP content from 0 to $30 \%(p<0.05)$. These indicated that Nano-HAP could promote the adsorption of BSA on microspheres including adsorption rate and adsorption quantity. As an example of PLA/20\% Nano-HAP composite microspheres, the kinetic behavior of BSA adsorption by microspheres was studied using dynamic data pretended in Fig. S4. The pseudo first order kinetic model, pseudo second order kinetic model and intraparticle diffusion model were proposed to clarify the adsorption kinetics. As shown in Fig. S5, the higher regression coefficient $\left(R^{2}\right)$ of 0.92072 demonstrated that the pseudo first order kinetic model was more appropriate to describe the dynamic behavior of protein adsorption on composite microspheres.

The adsorption of BSA on microspheres was further determined with varying BSA concentration. As shown in Fig. 5, PLA and PLA/Nano-HAP microspheres displayed similar adsorption profiles for BSA with the increase of BSA concentration. While BSA concentration was increased from 0.2 to $2.0 \mathrm{mg} / \mathrm{mL}$, the adsorption quantity was quickly

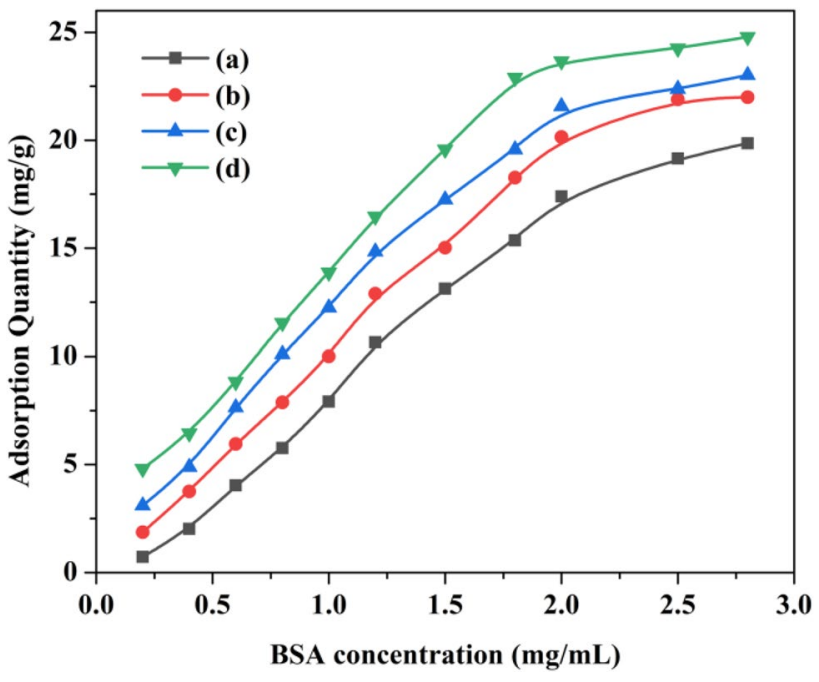

Fig. 5 The variation of BSA adsorption on microspheres with concentration. (a): pure PLA; (b): PLA/10\% Nano-HAP; (c): PLA/20\% Nano-HAP; (d): PLA/30\% Nano-HAP

enhanced. With BSA concentration over $2.0 \mathrm{mg} / \mathrm{mL}$, the change of adsorption quantity became flat. Differently, PLA/Nano-HAP composite microspheres exhibited higher adsorption quantity for BSA than pure PLA microspheres. Moreover, the larger content of Nano-HAP led to higher adsorption quantity. Accordingly, the incorporation of Nano-HAP in PLA was beneficial for the adsorption of BSA on microspheres. The adsorption isotherm studies were done for pure PLA microspheres and PLA/20\% Nano-HAP composite microspheres using the data shown in Fig. 5. Langmuir model, Freundlich model and Templin model were considered to describe the equilibrium behavior of microspheres (Fig. S6). Results showed that the adsorptions of PLA microspheres and composite microspheres for BSA were all most fitted to Langmuir type adsorption isotherm model.

\subsection{In vitro cellular evaluation}

As shown in Fig. 6, PLA microspheres and PLA/Nano-HAP composite microspheres could both support cells adhesion. However, PLA/Nano-HAP composite microspheres showed better adhesion and proliferation of rMSCs than PLA microspheres. This could be attributed to the component of Nano-HAP in PLA microspheres [19]. Moreover, the rough surface due to the incorporation of Nano-HAP might promote the adhesion of rMSCs [20-22].

In addition, results (Fig. 7) demonstrated that NanoHAP showed a facilitation on osteogenic differentiation of rMSCs. After 7 days and 14 days of cell culture (Fig. 7a-d), PLA/Nano-HAP sample displayed more positive staining area for ALP activity compared with pure 
Fig. 6 Cell adhesion on PLA and PLA/Nano-HAP samples

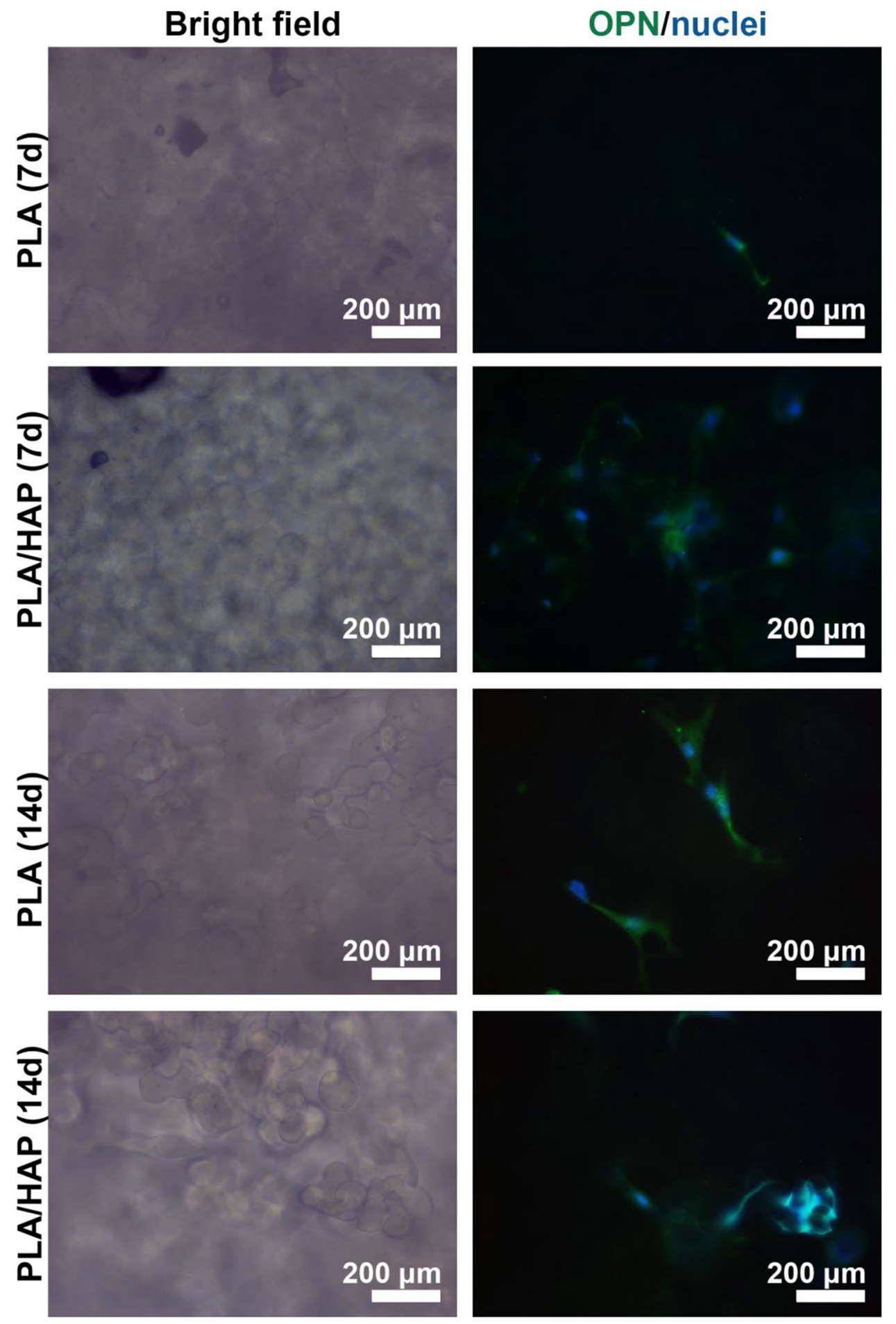

PLA sample, indicating Nano-HAP markedly promoted osteogenic differentiation of rMSCs. The mineralized nodules stained positive for alizarin red on PLA/NanoHAP sample further proved the expression of osteogenic phenotype of cells under the effect of Nano-HAP (Fig. 7e). SEM images exhibited details of cell adhesion and mineralized nodules. Spindle cell and its outspread pseudopods were observed on PLA/Nano-HAP sample (Fig. 7f). Moreover, some small particles secreted by cells were found on the surface of cells, and the acceleration and agglomeration of these particles formed the mineralized nodules (Fig. $7 \mathrm{~g}$ ). 
Fig. 7 a ALP staining of PLA sample on 7 days , b ALP staining of PLA/HAP sample on 7 days, $c$ ALP staining of PLA sample on 14 days, d ALP staining of PLA/HAP sample on 14 days, e mineralized nodules stained with alizarin red on PLA/HAP sample, $\mathbf{f}$ and $\mathbf{g}$ SEM images of cells on PLA/HAP sample
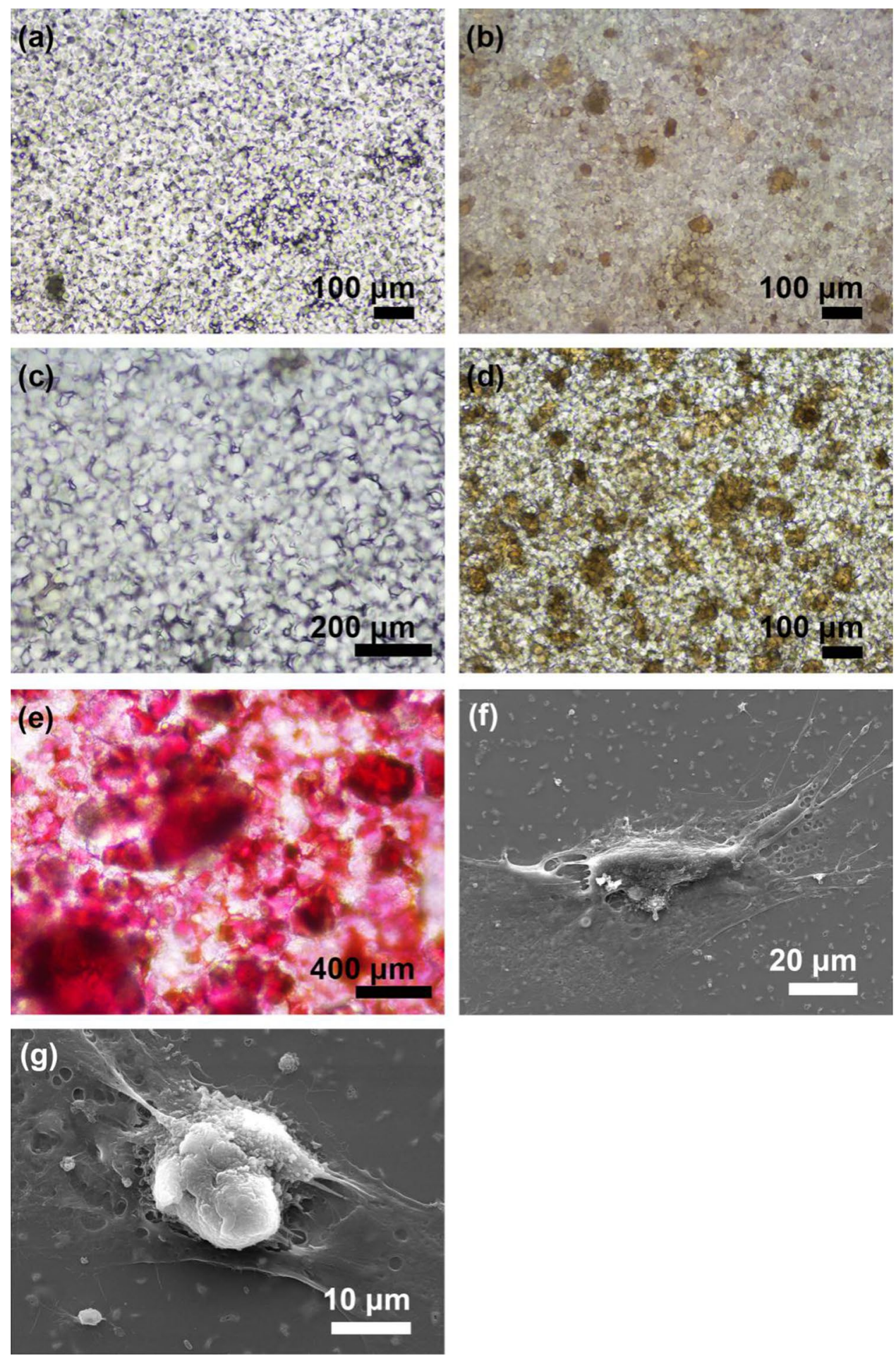

\section{Conclusions}

PLA/Nano-HAP composite microspheres were successfully prepared, achieving the embedding of Nano-HAP particles of $10-30 \%$ content in PLA microspheres. Results showed the increases of surface hydrophilicity and surface rough of microspheres depending on the content of Nano-HAP.
Moreover, the incorporation of Nano-HAP promoted the adsorption capacity of PLA microspheres for BSA. The protein adsorption on PLA/Nano-HAP composite microspheres followed pseudo first order kinetic model and Langmuir adsorption isotherm model. Cell culture experimental results showed that PLA/Nano-HAP composite microspheres had higher cell adhesion and proliferation 
compared to pure PLA microspheres. The addition of Nano-HAP can markedly promote osteogenic differentiation of rMSCs. Accordingly, PLA/Nano-HAP composite microsphere with an improved ability for bone regeneration can be used as a promising material for bone tissue engineering.

\section{Supplementary information}

Supplementary information is provided including XRD, FTIR and TEM of Nano- HAP and the SEM of the PLA/NanoHAP composite microspheres, particle size distribution of composite microspheres and adsorption data.

Acknowledgements This work was supported by the National Key Research and Development Program of China (Grant \#2016YFB1101300) and by the Science and Technology Partnership Program of Ministry of Science and Technology of China (Grant \#KY201602002).

\section{Compliance with ethical standards}

Conflict of interest The authors declare no competing financial interest.

\section{References}

1. Wei G, Ma PX (2004) Structure and properties of nanohydroxyapatite/polymer composite scaffolds for bone tissue engineering. Biomaterials 25(19):4749-4757

2. Khan F, Ahmad SR (2013) Chapter 5 Bioactive polymers and nanobiomaterials composites for bone tissue engineering, biomimetics: advancing nanobiomaterials and tissue engineering. Wiley, Hoboken

3. Fu C, Yang X, Tan S, Song L (2017) Enhancing cell proliferation and osteogenic differentiation of MC3T3-E1 pre-osteoblasts by BMP-2 delivery in graphene oxide-incorporated PLGA/HA biodegradable microcarriers. Sci Rep 7:12549

4. Szcześ A, Ho L, Chibowski E (2017) Synthesis of hydroxyapatite for biomedical applications. Adv Colloid Interface 249:321-330

5. Kucharska M, Walenko K, Lewandowska-szumiel M, Brynk T (2015) Chitosan and composite microsphere-based scaffold for bone tissue engineering: evaluation of tricalcium phosphate content influence on physical and biological properties. J Mater Sci Mater Med 26:143

6. Ni P, Bi H, Zhao G, Han Y, Wickramaratne MN, Dai H, Wang X (2019) Electrospun preparation and biological properties in vitro of polyvinyl alcohol/sodium alginate/nano-hydroxyapatite composite fiber membrane. Colloid Surf B 173:171-177

7. Santana-Melo GF, Rodrigues BVM, Silva E, Ricci R, Marciano FR, Webster TJ, Vasconcellos LMR, Lobo AO (2017) Electrospun ultrathin PBAT/nHAp fibers influenced the in vitro and in vivo osteogenesis and improved the mechanical properties of neoformed bone. Colloid Surf B 155:544-552
8. Cunniffe GM, Curtin CM, Thompson EM, Dickson GR, O'Brien FJ (2016) Content-dependent osteogenic response of nanohydroxyapatite: an in vitro and in vivo assessment within collagenbased scaffolds. ACS Appl Mater Interfaces 8:23477-23488

9. Nagata F, Miyajima T, Teraoka K, Yokogawa Y (2005) Preparation of porous poly (lactic acid)/hydroxyapatite microspheres intended for injectable bone substitutes. Key Eng Mater 284-286:819-822

10. Lee TJ, Kang SW, Bhang SH, Kang JM, Kim BS (2010) Apatitecoated porous poly(lactic-co-glycolic acid) microspheres as an injectable bone substitute. J Biomater Sci-Polym E 21:635-645

11. Lee YK (2010) Nanocomposite microspheres of PLGA/HA with antibiotics for injectable bone-graft materials. Tissue Eng Regen Med 7:561-565

12. Ahmed I (2015) Development of microspheres for biomedical applications : a review. Prog Biomater 4:1-19

13. Liao HB, Lanao RPF, van den Beucken JJJP, Zhou N, Both SK, Wolke JGC, Jansen JA (2016) Size matters: effects of PLGAmicrosphere size in injectable CPC/PLGA on bone formation. $J$ Tissue Eng Regen M 10:669-678

14. Poorraeisi M, Afshar A (2019) Synthesizing and comparing HA$\mathrm{TiO}_{2}$ and $\mathrm{HA}-\mathrm{ZrO}_{2}$ nanocomposite coatings on 316 stainless steel. SN Appl Sci 1:155

15. Sundarabharathi L, Ponnamma D, Parangusan $\mathrm{H}$ et al (2020) Effect of anions on the structural, morphological and dielectric properties of hydrothermally synthesized hydroxyapatite nanoparticles. SN Appl Sci 2:94

16. Kandori K, Mukai M, Yasukawa A, Ishikawa T (2000) Competitive and cooperative adsorptions of bovine serum albumin and lysozyme to synthetic calcium hydroxyapatites. Langmuir 16:2301-2305

17. Boonsongrit $Y, A$ be $H$, Sato $K$, Naito $M$, Yoshimura $M$, Ichikawa $H$, Fukumori Y (2008) Controlled release of bovine serum albumin from hydroxyapatite microspheres for protein delivery system. Mater Sci Eng B-Adv 148:162-165

18. Tanaka T, Takai Y, Nagase A, Teraguchi K, Minbu H, Ochiai A, Kimura I, Taniguchi M (2019) Protein adsorption characteristics of nanoparticle-assembled hollow microspheres of hydroxyapatite and their composites with PLLA microporous membranes. Heliyon 5:e01490

19. Lee W, Loo C, Zavgorodniy AV, Ghadiri M (2013) A novel approach to enhance protein adsorption and cell proliferation on hydroxyapatite : citric acid treatment. RSC Adv 3:4040-4051

20. Fan YW, Cui FZ, Chen LN, Zhai Y, Xu QY, Lee IS (2002) Adhesion of neural cells on silicon wafer with nano-topographic surface. Appl Surf Sci 187:313-318

21. Alves CM, Yang Y, Marton D, Carnes DL, Ong JL, Sylvia VL, Dean DD, Reis RL, Agrawal CM (2008) Plasma surface modification of poly ( $D, L$-Lactic Acid) as a tool to enhance protein adsorption and the attachment of different cell types. J Biomed Mater Res B Appl Biomater 87:59-66

22. Baek SM, Shin MH, Moon J, Jung HS, Lee SA, Hwang W, Yeom JT, Hahn SK, Kim HS (2017) Superior pre-osteoblast cell response of etched ultrafine-grained titanium with a controlled crystallographic orientation. Sci Rep 7:44213

Publisher's Note Springer Nature remains neutral with regard to jurisdictional claims in published maps and institutional affiliations. 